\title{
Hydroxypropyl Methylcellulose-Based Edible Coatings Formulated with Antifungal Food Additives to Reduce Alternaria Black Spot and Maintain Postharvest Quality of Cold-Stored 'Rojo Brillante' Persimmons
}

\author{
Asunción Fernández-Catalán, Lluís Palou (D), Verònica Taberner, Amparo Grimal, Maricruz Argente-Sanchis and \\ María B. Pérez-Gago *D \\ Centre de Tecnologia Postcollita (CTP), Institut Valencià d'Investigacions Agràries (IVIA), 46113 Montcada, \\ Valencia, Spain; fernandez_asucat@externos.gva.es (A.F.-C.); palou_llu@gva.es (L.P.); taberner_ver@gva.es (V.T.); \\ amgrimo@gmail.com (A.G.); argente_mcrsan@gva.es (M.A.-S.) \\ * Correspondence: perez_mbe@gva.es; Tel.: +34-963424118
}

check for updates

Citation: Fernández-Catalán, A.; Palou, L.; Taberner, V.; Grimal, A.; Argente-Sanchis, M.; Pérez-Gago, M.B. Hydroxypropyl Methylcellulose-Based Edible Coatings Formulated with Antifungal Food Additives to Reduce Alternaria Black Spot and Maintain Postharvest Quality of Cold-Stored 'Rojo Brillante' Persimmons. Agronomy 2021, 11, 757. https://doi.org/10.3390/agronomy 11040757

Academic Editors: Anna Kocira and Katarzyna Panasiewicz

Received: 16 March 2021

Accepted: 9 April 2021

Published: 13 April 2021

Publisher's Note: MDPI stays neutral with regard to jurisdictional claims in published maps and institutional affiliations.

Copyright: (c) 2021 by the authors. Licensee MDPI, Basel, Switzerland. This article is an open access article distributed under the terms and conditions of the Creative Commons Attribution (CC BY) license (https:/ / creativecommons.org/licenses/by/ $4.0 /)$.
Abstract: Composite edible coatings based on hydroxypropyl methylcellulose (HPMC), as a polymeric phase, and oleic acid (OA) or beeswax (BW), as a hydrophobic phase, were formulated with different food additives as antifungal ingredients. HPMC-OA coatings containing $2 \%(w / v)$ sodium benzoate (SB), 1\% ammonium carbonate (AC), 1\% potassium carbonate (PC), 1\% potassium bicarbonate (PBC), 1\% sodium bicarbonate (SBC), $1 \%$ potassium silicate (PSi), $0.1 \%$ sodium methyl paraben (SMP) or $0.1 \%$ sodium ethyl paraben (SEP), and HPMC-BW coatings containing $2 \%$ sodium propionate (SP), $2 \%$ PBC, $2 \%$ SB or $0.1 \%$ SEP were evaluated for the control of Alternaria black spot (ABS) on Diospyros kaki Thunb. 'Rojo Brillante' persimmons artificially inoculated with Alternaria alternata. After 14 days of incubation at $20^{\circ} \mathrm{C}, \mathrm{HPMC}-\mathrm{OA}$ coatings formulated with PBC, PC or SEP were the most effective to reduce ABS incidence $(61,54$, and $36 \%$ reduction, respectively, concerning uncoated control fruit) and severity $(28,12$ and $22 \%$ reduction, respectively), while only HPMC-BW coatings formulated with SEP significantly reduced ABS incidence ( $50 \%$ reduction) and severity ( $36 \%$ reduction). HPMC-OA and HPMC-BW coatings containing $2 \%$ PBC or $0.1 \%$ SEP were selected to evaluate their effect on the weight loss, firmness and respiration rate of healthy 'Rojo Brillante' persimmons cold-stored at $1{ }^{\circ} \mathrm{C}$ and $90 \%$ relative humidity (RH) for 15 and 30 days, followed by 7 days of shelf life at $20^{\circ} \mathrm{C}$. HPMC-BW coatings were more effective in reducing fruit weight and firmness losses than HPMC-OA coatings, while all antifungal coatings significantly reduced fruit respiration. Overall, the HPMC-BW edible coating that contains SEP could be a promising postharvest treatment to control ABS and maintain the quality of cold-stored 'Rojo Brillante' persimmons.

Keywords: Diospyros kaki; Alternaria alternata; alternative postharvest disease control; generally recognized as safe (GRAS) substances; postharvest quality

\section{Introduction}

More than 5 million tons of persimmons (Diospyros kaki Thunb.) are produced in the world, of which approximately 492,320 tons are produced in Spain, being the second largest producing country and the main exporter in the world [1]. Persimmon production in Spain is mainly located in the Valencia and Andalucía regions, and the production under the Denomination of Origin "Kaki Ribera del Xuquer" area (Ribera Alta, Valencia) is especially significant. The entire crop in this area is primarily of the 'Rojo Brillante' cultivar, and the production has increased fourfold over the last decade [2], becoming a profitable alternative crop for fruit growers. The most important reason for this increase is the implementation of deastringency technology, based on the application of carbon dioxide $\left(\mathrm{CO}_{2}\right)$ concentrations higher than $95 \%$ at $20^{\circ} \mathrm{C}$ for $24 \mathrm{~h}$ [3], to effectively remove fruit astringency while maintaining the crisp texture, allowing the export of the product. 
The cultivar 'Rojo Brillante' has a short harvest period (between October and December). Nowadays, the main interest of the industry is to extend the marketing period of the fruit to reach off-season markets, and technologies such as the application of 1-methylcyclopropene (1-MCP) in combination with cold storage are being used at a commercial scale to reduce chilling injury and maintain fruit firmness. However, 'Rojo Brillante' persimmons are quite susceptible to postharvest diseases caused by a number of fungal pathogens, and substantial postharvest losses due to decay (up to $30 \%$ of fruit) have been reported in commercial packing houses in the Valencia area [4,5]. Among them, Alternaria alternata (Fr.) Keissler, causing postharvest Alternaria black spot (ABS), is the most important fungal pathogen affecting 'Rojo Brillante' persimmon in Spain. Decay symptoms during storage at $0-5{ }^{\circ} \mathrm{C}$ are superficial, small black spots in the calyx and throughout the fruit peel that may expand rapidly during shelf life at $20^{\circ} \mathrm{C}$ [4].

The use of synthetic chemical fungicides to control fungal spoilage of fresh horticultural products has been practiced for many years. However, significant problems regarding the proliferation of fungicide-resistant strains of the pathogens, and concerns about chemical residues on or in produce and in the environment have led to the restriction and even prohibition of many synthetic fungicides in a number of countries, and especially in the European Union [6]. Thus, nowadays, the use of fungicides is not permitted for the postharvest treatment of persimmon in Spain; with the exception of pyrimethanil, which has been allowed as an emergency registration for the last seasons precisely due to the high incidence of ABS and the consequent important economic losses. The industry is therefore very interested in the development of new strategies to control ABS. As an alternative to fungicide treatments, the use of food preservative agents is a relatively new trend for controlling postharvest disease in fresh horticultural produce. These agents are natural or synthetic compounds with known and low toxicity, classified as food-grade additives or generally recognized as safe (GRAS) compounds by national and international authorities [6]. The application of these agents to agricultural products is typically by dipping in aqueous solutions [7] or as ingredients of edible coatings [8].

In recent years, the release of antimicrobial agents incorporated into biodegradable edible films and coatings has emerged as a new, effective, and environmentally friendly alternative aimed at extending the shelf life of many food products, including fresh fruit and vegetables [9]. Composite coatings based on polysaccharides or proteins and lipids are usually used for fruit and vegetables. These coatings form a semi-permeable barrier to gases and water vapor that reduces fruit respiration and weight loss, helps maintain firmness, reduces chilling injury and other physiological disorders, and provides gloss [10]. Furthermore, the addition of antimicrobial food preservatives such as essential oils, natural extracts, organic acids and their salts, parabens, polypeptides, or chitosan to these composite matrixes can improve the functional properties of the coatings, by inhibiting the growth of bacteria, yeasts, and molds during the storage and distribution of fresh fruit and vegetables [11-14].

In previous works, our research group has developed antifungal hydroxypropyl methylcellulose (HPMC)-lipid edible coatings containing several mineral salts, organic acid salts, and paraben salts, all classified as food additives or GRAS compounds with effectiveness against fungal pathogens causing postharvest decay of citrus [10,15-18], plums $[6,19]$ or cherry tomatoes $[8,9,20]$. It was observed in these works that the effect of the coatings on the control of postharvest decay and maintenance of fruit quality during storage depended on the coating composition (i.e., type and amount of lipid and minor ingredients, antifungal compounds, total solid content, etc.), type and properties of the fruit (i.e., species and even cultivar) and target pathogen. For example, on cherry tomatoes in vitro (i.e., first screening test to select GRAS salts) and in vivo studies (i.e., fruit inoculated with the pathogen and coated with the antifungal edible coatings) were used to select effective antifungal edible coatings for the control of black spot caused by A. alternata [8]. Among them, an HPMC-based coating containing the GRAS salt sodium benzoate (SB) was effective in controlling fungal growth, and also to reduce weight loss and respiration rate 
of cherry tomatoes during cold storage at $5^{\circ} \mathrm{C}$, and shelf life at $20^{\circ} \mathrm{C}$, without negatively affecting other quality attributes [9].

Other antifungal edible coatings containing plant extracts, natamycin, and essential oils have also been developed to reduce postharvest black spot caused by A. alternata on fresh fruit such as avocado [21], jujube fruit [22], persimmon [23], and tomato [24]. In persimmon fruit, starch-gellan coating formulations reduced the incidence of $A B S$ on inoculated fruits during storage at $20^{\circ} \mathrm{C}$, although the treatment with thyme essential oil did not have any significant effect [23]. To our knowledge, beyond these works, there is no information available on the development of new edible composite coatings with the addition of antifungal GRAS compounds to control persimmon postharvest black spot. Therefore, the objective of this work was to develop new HPMC-lipid edible composite coatings containing selected food additives with antifungal properties effective in reducing the development of ABS on 'Rojo Brillante' persimmons artificially inoculated with the pathogen and preserve the quality of intact fruit cold-stored at commercial conditions.

\section{Materials and Methods}

\subsection{Materials}

Hydroxypropyl methylcellulose (HPMC) (Methocel E19) was purchased from Dow Chemical Co. (Midland, MI, USA). Beeswax (BW, grade 1) was supplied by Fomesa Fruitech S.L. (Valencia, Spain). Oleic acid (OA), glycerol and stearic acid were purchased from Panreac Química S.L.U. (Barcelona, Spain). Food preservatives used in this work are given in Table 1, and included mineral salts, organic acid salts and sodium salts of parabens. All the ingredients are likewise classified as food additives or GRAS compounds by the European Union and the United States Food and Drug Administration (US FDA). Laboratory reagent grade preservatives ( $99 \%$ minimum purity) were purchased from Sigma-Aldrich Chemie, Fluka Chemie AG (Buchs, Switzerland), Panreac Química S.L.U., or Merck KGaA (Darmstadt, Germany). Potassium silicate (PSi) was purchased from PQ Corporation (Valley Forge, PA, USA) as the commercial product Sil-Matrix ${ }^{\circledR}(29 \%$ PSi).

Table 1. Composition, $\mathrm{pH}$, and viscosity of hydroxypropyl methylcellulose (HPMC)-lipid edible composite emulsions containing antifungal food preservatives evaluated to control Alternaria black spot on artificially inoculated 'Rojo Brillante' persimmons incubated at $20^{\circ} \mathrm{C}$.

\begin{tabular}{|c|c|c|c|c|c|}
\hline Coating & Food Preservative & $\begin{array}{c}\text { Food Preservative } \\
\text { Concentration } \\
(\%, w b)\end{array}$ & $\begin{array}{l}\text { Solid Concentration } \\
(\%, w b)\end{array}$ & $\mathrm{pH}$ & $\begin{array}{l}\text { Viscosity } \\
\text { (mPa.s) }\end{array}$ \\
\hline \multirow{8}{*}{$\mathrm{HPMC}-\mathrm{OA}$} & Ammonium carbonate (AC) & 1.0 & 8 & 7.39 & 111.6 \\
\hline & Potassium carbonate (PC) & 1.0 & 8 & 9.83 & 134.1 \\
\hline & Potassium bicarbonate (PBC) & 1.0 & 8 & 8.03 & 101.5 \\
\hline & Sodium benzoate (SB) & 2.0 & 9 & 6.05 & 110.3 \\
\hline & Sodium bicarbonate (SBC) & 1.0 & 8 & 7.97 & 112.6 \\
\hline & Potassium silicate (PSi) & 1.0 & 8 & 9.36 & 111.8 \\
\hline & Sodium methyl paraben (SMP) & 0.1 & 7.1 & 7.26 & 109.4 \\
\hline & Sodium ethyl paraben (SEP) & 0.1 & 7.1 & 6.96 & 104.1 \\
\hline \multirow{4}{*}{ HPMC-BW } & Potassium bicarbonate (PBC) & 2.0 & 11 & 8.68 & 163.0 \\
\hline & Sodium propionate (SP) & 2.0 & 11 & 6.47 & 174.4 \\
\hline & Sodium benzoate (SB) & 2.0 & 11 & 6.39 & 149.1 \\
\hline & Sodium ethyl paraben (SEP) & 0.1 & 8.1 & 7.56 & 150.7 \\
\hline
\end{tabular}

Lipids: oleic acid (OA) and beeswax (BW).

\subsection{Formulation and Preparation of Antifungal Coatings}

To determine the effect of the antifungal HPMC-lipid edible composite coatings on the development of $\mathrm{ABS}$, two experiments were performed with coating formulations that varied in lipid type (OA or $\mathrm{BW})$, antifungal agents and other minor ingredients. Base formulations (i.e., HPMC-OA and HPMC-BW without antifungal agents) were selected in preliminary assays to ensure emulsion stability and fruit surface wetting (data not shown). Selected food preservatives were incorporated into HPMC-OA and HPMC-BW coatings at the concentrations listed in Table 1. HPMC-OA edible composite emulsions were prepared 
with glycerol and Tween 80 as a plasticizer and emulsifier, respectively. These formulations contained 20\% OA (dry basis (db)) and the ratios of HPMC-glycerol (2:1) (db) and OATween $80(1: 1)(\mathrm{db})$ were kept constant throughout the study. HPMC-BW edible composite emulsions were prepared with glycerol as a plasticizer and stearic acid and Tween 80 as emulsifiers at a ratio of $1: 1$. These formulations contained $30 \% \mathrm{BW}(\mathrm{db})$, and the ratios of HPMC-glycerol (3:1) (db) and BW-stearic acid/Tween 80 (3:1) (db) were kept constant throughout the study. In all the emulsions, water was added to bring the mixtures to the final solid content shown in Table 1.

All the emulsions were prepared by combining the hydrophilic phase (HPMC) and the hydrophobic phase (OA or BW) suspended in water. Briefly, the aqueous solution of HPMC was prepared by dispersing the HPMC at the corresponding concentration for each base formulation (2.8\% and 3.4\% $w / w$ for HPMC-OA and HPMC-BW, respectively) in hot water at $90{ }^{\circ} \mathrm{C}$, and later hydration at $20^{\circ} \mathrm{C}$. Mixtures with the lipid, plasticizer, and emulsifiers were heated to $90-95^{\circ} \mathrm{C}$ to ensure complete melting of the lipids, and emulsions were formed by homogenization with a high-shear probe mixer (Ultra-Turrax, model T25, IKA-Werke, Staufen, Germany) for $1 \mathrm{~min}$ at 12,000 rpm and $3 \mathrm{~min}$ at 22,000 rpm. After adding the corresponding antifungal food additives, formulations were cooled to a temperature below $25^{\circ} \mathrm{C}$ by placing them for $25 \mathrm{~min}$ in an ice-water bath with continuous agitation to ensure complete hydration of the HPMC. The emulsions were kept for 1 day at $5{ }^{\circ} \mathrm{C}$ before use. The $\mathrm{pH}$ of the emulsions was measured with a digital $\mathrm{pH}$-meter (Consort C830, Turnhout, Belgium) and viscosity was measured with a viscometer at $20^{\circ} \mathrm{C}$ (Visco Star Plus R, Fungilab, Barcelona, Spain). The stability of the formulations was tested according to the method described by Valencia-Chamorro et al. [15]. Briefly, the emulsions were placed in $100 \mathrm{~mL}$ volumetric tubes and phase separation was evaluated after $24 \mathrm{~h}$ at $25^{\circ} \mathrm{C}$. Three replicate emulsions were measured.

\subsection{Effect of Coatings on Disease Development}

\subsubsection{Fungal Inoculum}

The strain QAV-6 of A. alternata was obtained from a decayed persimmon in a Valencian packing house and maintained in the fungal culture collection of the Centre de Tecnologia Postcollita (CTP) of the Institut Valencià d'Investigacions Agràries (IVIA). This isolate was selected for its aggressiveness and uniform behavior on persimmon fruit, and deposited in the Spanish Type Culture Collection (CECT, University of Valencia, Valencia, Spain) with the accession number CECT 21106. Prior to each experiment, the fungal isolate was grown on potato dextrose agar (PDA; Sigma-Aldrich Chemie, Steinheim, Germany) Petri dishes at $25^{\circ} \mathrm{C}$ in the dark for 7-14 days. From this culture, a high-density conidial suspension was prepared in Tween 80 (0.05\% w/v; Panreac-Química S.A., Barcelona, Spain) and sterile water. This suspension was passed through two layers of cheesecloth, measured with a hemacytometer (Fuchs-Rosenthal; Hirschmann EM Techcolor, Eberstadt, Germany), and diluted with sterile water to achieve an inoculum density of $1 \times 10^{6}$ spores $/ \mathrm{mL}$ of A. alternata.

\subsubsection{Fruit Inoculation and Coating Application}

Persimmons (Diospyros kaki Thunb.) cv. 'Rojo Brillante' grown in the L'Alcúdia area (Ribera Alta, Valencia, Spain) were harvested at commercial maturity, transported to the CTP IVIA facilities, and stored for up to $24 \mathrm{~h}$ at room temperature until further use. Two different experiments were performed and repeated, one with HPMC-OA coatings (8 different coatings) and another with HPMC-BW coatings (4 different coatings) (Table 1). Before each experiment, fruit was selected, randomized, the surface was disinfected (4minute dips in $0.5 \%$ sodium hypochlorite aqueous solution), thoroughly rinsed with tap water, and allowed to air-dry at room temperature. Disinfected fruit, placed on sanitized plastic cavity sockets, were superficially wounded in three equidistant points in the same cheek of the fruit using a sterilized stainless-steel rod with a probe tip $1 \mathrm{~mm}$ wide and $2 \mathrm{~mm}$ in length. Each peel wound was inoculated with $20 \mu \mathrm{L}$ of the conidial suspension of 
A. alternata with a micropipette. Once the inoculum drops were air-dried, inoculated fruit were incubated for $24 \mathrm{~h}$ at $20^{\circ} \mathrm{C}$ and $90 \%$ relative humidity (RH) to favor effective infection and simulate recent field infections. After this period, fruit was individually coated by pipetting $400 \mathrm{~mL}$ of coating material onto each fruit, and rubbing with gloved hands to simulate spray coating application in industrial packing-line roller conveyors [25]. Coated fruit was drained and allowed to air-dry at room temperature. Inoculated but uncoated persimmons were used as controls. In each experiment, edible coatings formulated without antifungal food preservatives were also evaluated as negative controls (HPMC-lipid). Coated and uncoated fruit were arranged on plastic cavity sockets on cardboard boxes and incubated for 14 days at $20^{\circ} \mathrm{C}$ and $90 \% \mathrm{RH}$. In each experiment, each treatment was applied to 4 replicates of 5 fruit each ( 15 peel wounds per replicate; total of 60 wounds per treatment). Each experiment was conducted twice.

\subsubsection{Determination of Disease Incidence and Severity}

The incidence of ABS was assessed as the number of infected wounds and reported as the percentage of incidence reduction with respect to the control treatments. Disease severity was determined as the diameter of the lesion $(\mathrm{mm})$ in each wound, and the results were reported as the percentage of severity reduction with respect to the control treatments. Disease incidence and severity were assessed after 7 and 14 days of incubation at $20^{\circ} \mathrm{C}$. Results after 14 days are presented.

\subsection{Effect of Coatings on Quality of Cold-Stored Persimmons \\ 2.4.1. Fruit Coating and Storage}

For the fruit quality study, potassium bicarbonate (PBC) at $2 \%(w / v)$ and sodium ethyl paraben $(\mathrm{SEP})$ at $0.1 \%(w / v)$ were selected as antifungal agents to be incorporated into the HPMC-OA and HPMC-BW coatings. These food additives were the most effective among those tested for antifungal activity on inoculated fruit. Considering the effect of $1 \%$ PBC in the HPMC-OA edible coating to reduce ABS incidence and severity of inoculated persimmon, and after confirming in a preliminary experiment that the incorporation of $2 \%$ PBC to this coating was possible in terms of compatibility and stability, we selected this highest concentration for the second experiment. Edible coatings formulated without antifungal agents were also considered for fruit quality evaluation. 'Rojo Brillante' persimmons were selected, randomized, washed with tap water, and allowed to air-dry at room temperature. Intact and healthy fruit were divided into seven groups of 60 fruit each, which corresponded to the six coating treatments (HPMC-OA and HPMC-BW with and without antifungal agents; Table 2) and one control treatment (uncoated fruit). Each group was divided into two batches of 30 fruit each for quality assessment during storage and after shelf life. Persimmons were coated as described above, drained of excess coating, left to dry at room temperature and stored for 1 month at $1{ }^{\circ} \mathrm{C}$ and $95 \% \mathrm{RH}$, followed by 7 days of shelf life at $20^{\circ} \mathrm{C}$. 
Table 2. Composition, $\mathrm{pH}$, and viscosity of selected hydroxypropyl methylcellulose (HPMC)-lipid edible composite emulsions with and without antifungal food preservatives evaluated to preserve fruit quality of 'Rojo Brillante' persimmons during storage at $1{ }^{\circ} \mathrm{C}$ and shelf life at $20^{\circ} \mathrm{C}$.

\begin{tabular}{|c|c|c|c|c|c|}
\hline Coating & Food Preservative & $\begin{array}{c}\text { Food Preservative } \\
\text { Concentration } \\
(\%, w b)\end{array}$ & $\begin{array}{c}\text { Solid } \\
\text { Concentration } \\
(\%, w b)\end{array}$ & $\mathrm{pH}$ & $\begin{array}{c}\text { Viscosity } \\
\text { (mPa.s) }\end{array}$ \\
\hline \multirow{3}{*}{ HPMC-OA } & - & - & 7.0 & 5.46 & 89.4 \\
\hline & Potassium bicarbonate (PBC) & 2.0 & 9.0 & 8.28 & 79.7 \\
\hline & Sodium ethyl paraben (SEP) & 0.1 & 7.1 & 6.72 & 98.9 \\
\hline \multirow{3}{*}{ HPMC-BW } & - & - & 9.0 & 5.58 & 193.4 \\
\hline & Potassium bicarbonate (PBC) & 2.0 & 11.0 & 8.84 & 137.5 \\
\hline & Sodium ethyl paraben (SEP) & 0.1 & 9.1 & 7.60 & 198.6 \\
\hline
\end{tabular}

Lipids: oleic acid (OA) and beeswax (BW).

\subsubsection{Assessment of Fruit Quality}

1. Weight loss. Lots of 20 fruit per treatment were used to measure weight loss. The same marked persimmon fruit was weighed at the beginning of the experiment (weight at harvest), after cold storage, and at the end of the 7-day shelf-life period at $20^{\circ} \mathrm{C}$. The results were expressed as the percentage loss of initial weight.

2. Fruit firmness. The firmness of 20 fruit per treatment was determined at harvest and after storage and shelf-life period using an Instron Universal testing machine (Model 4301, Instron Corp., Canton, MA, USA). A thin disk of skin of about $2 \mathrm{~cm}$ in diameter was removed from each of the opposite cheeks of the fruit, and firmness was determined as the maximum force in Newtons $(\mathrm{N})$ required to penetrate the fruit flesh with a plunger of $8 \mathrm{~mm}$ in diameter.

3. Respiration rate. The respiration of coated and uncoated persimmons was measured by the closed system. Four replicates of 3 fruit each were used to determine the $\mathrm{CO}_{2}$ production at harvest and at the end of the shelf-life period. Samples were weighed and placed in sealed containers of known volume. The accumulation of $\mathrm{CO}_{2}$ in the headspace atmosphere was measured at $20^{\circ} \mathrm{C}$ over a period of $2 \mathrm{~h}$. The gas sample (1 mL) was injected into a gas chromatograph (GC) (Thermo Trace, Thermo Fisher Scientific, Inc. Waltham, MA, USA) equipped with a thermal conductivity detector (TCD) and fitted with a Poropack QS80/100 column $(1.2 \mathrm{~m} \times 0.32 \mathrm{~cm}$ internal diameter). Temperatures were 35,115 , and $150{ }^{\circ} \mathrm{C}$ for the oven, injector, and thermal conductivity detector, respectively. Helium was used as a carrier gas at a flow rate of $22 \mathrm{~mL} / \mathrm{min}$. The $\mathrm{CO}_{2}$ concentration was calculated using the peak area obtained from a standard gas mixture of 15.0:2.5\% $\mathrm{O}_{2}: \mathrm{CO}_{2}$. Results were expressed as $\mathrm{mg} \mathrm{CO}_{2} / \mathrm{kg} \mathrm{h}$.

\subsection{Statistical Analysis}

Statistical analysis was performed using the software Statgraphics Centurion XVII (Statgraphics Technologies Inc., The Plains, VA, USA). Mean differences were determined by Fisher's protected least significant difference test (LSD, $p<0.05)$ applied after analysis of variance (ANOVA). For disease incidence data, ANOVA was applied to the arcsine of the square root of the percentage of infected fruit in order to assure the homogeneity of variances. Non-transformed means are shown.

\section{Results}

\subsection{Effect of Coatings on Disease Development}

The effect of the different HPMC-OA and HPMC-BW edible coatings containing food preservatives on $\mathrm{ABS}$ development on persimmon artificially inoculated with A. alternata and stored for 14 days at $20^{\circ} \mathrm{C}$ is shown in Figure 1 for incidence reduction (reduction in the number of infected wounds with respect to control fruit, \%) and in Table 3 for severity reduction (reduction in lesion diameter with respect to control fruit, \%). After 14 days of incubation at $20^{\circ} \mathrm{C}$, the HPMC-OA coatings significantly reduced ABS incidence 
compared with uncoated samples, except those containing sodium bicarbonate (SBC), PSi, and sodium methyl paraben (SMP). The HPMC-OA coatings formulated with potassium carbonate (PC), PBC, and SEP were the most effective, with reductions of disease incidence compared to control samples of 54, 61, and 36\%, respectively (Figure 1a). In the case of the HPMC-BW coatings, only the coating formulated with SEP was effective in reducing the incidence of $\mathrm{ABS}$ on inoculated persimmons, with a reduction of around $50 \%$ (Figure $1 \mathrm{~b}$ ).

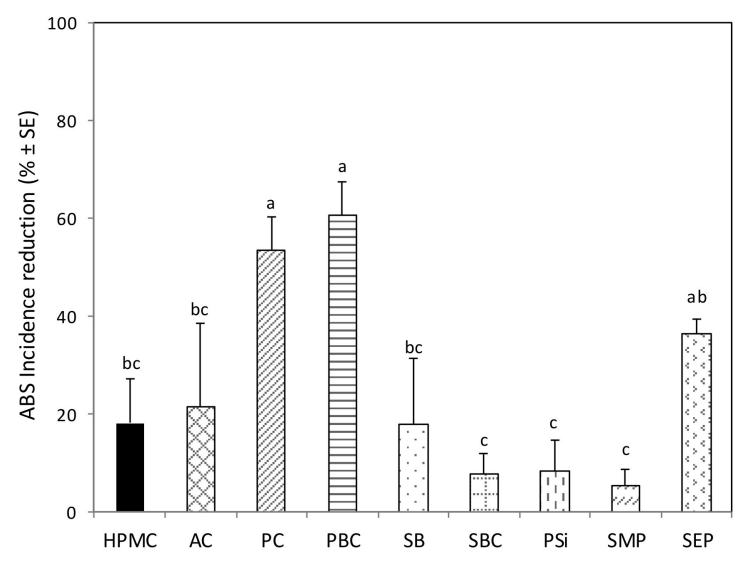

(a)

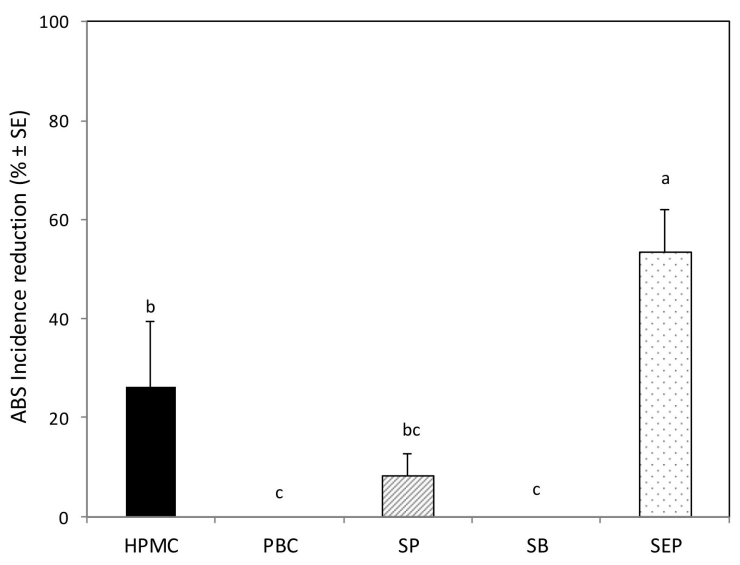

(b)

Figure 1. Reduction in Alternaria black spot (ABS) incidence ( $\% \pm \mathrm{SE})$ with respect to control fruit on 'Rojo Brillante' persimmons artificially inoculated with Alternaria alternata, coated $24 \mathrm{~h}$ later with hydroxypropyl methylcellulose (HPMC)oleic acid (OA) (a) and HPMC-beeswax (BW) (b) composite edible coatings containing antifungal food additives, and incubated for 14 days at $20{ }^{\circ} \mathrm{C}$ and $90 \%$ RH. Represented additives and concentrations are: $1 \%$ ammonium carbonate (AC), $1 \%$ potassium carbonate (PC), $1 \%$ and $2 \%$ potassium bicarbonate (PBC) for HPMC-OA and HPMC-BW, respectively, $2 \%$ sodium benzoate (SB), $1 \%$ sodium bicarbonate (SBC), $1 \%$ potassium silicate (PSi), $0.1 \%$ sodium methyl paraben (SMP), $0.1 \%$ sodium salt of ethyl paraben (SEP), $2 \%$ sodium propionate (SP) and $2 \%$ sodium benzoate (SB). HPMC indicates coating without any antifungal agent. For each experiment, (a) and (b), values are means of two repeated assays. Mean ABS incidence on control fruit (uncoated) was $82.5 \pm 8.5 \%$ and $71.7 \pm 5.0 \%$ for experiments $\mathrm{A}$ and $\mathrm{B}$, respectively. For each experiment, columns with different letters are significantly different according to Fisher's protected LSD test $(p<0.05)$ applied after an ANOVA.

Table 3. Severity reduction with respect to control fruit (uncoated) of Alternaria black spot on 'Rojo Brillante' persimmons artificially inoculated with Alternaria alternata, coated $24 \mathrm{~h}$ later with hydroxypropyl methylcellulose (HPMC)-oleic acid (OA) or HPMC-beeswax (BW) composite edible coatings containing antifungal food additives, and incubated for 14 days at $20^{\circ} \mathrm{C}$ and $90 \% \mathrm{RH}$.

\begin{tabular}{ccc}
\hline & \multicolumn{2}{c}{$\begin{array}{c}\text { Disease Severity Reduction } \\
\text { Food Additive }\end{array}$} \\
\cline { 2 - 3 } & HPMC-OA & HPMC-BW \\
\hline None (HPMC-lipid) & $0.0 \pm 0.0^{\mathrm{c}} \mathbf{\text { SE) }}$ \\
\hline Ammonium carbonate (AC) & $0.0 \pm 0.0^{\mathrm{b}}$ & $25.9 \pm 0.8^{\mathrm{ab}}$ \\
Potassium carbonate (PC) & $11.8 \pm 0.7^{\mathrm{b}}$ & - \\
Potassium bicarbonate (PBC) & $27.9 \pm 0.5^{\mathrm{a}}$ & - \\
Sodium benzoate (SB) & $1.5 \pm 1.2^{\mathrm{c}}$ & $14.7 \pm 1.5^{\mathrm{b}}$ \\
Sodium bicarbonate (SBC) & $0.0 \pm 0.0^{\mathrm{c}}$ & - \\
Potassium silicate (PSi) & $0.0 \pm 0.0^{\mathrm{c}}$ & - \\
Sodium methyl paraben (SMP) & $0.0 \pm 0.0^{\mathrm{c}}$ & - \\
Sodium salt of ethyl paraben (SEP) & $22.1 \pm 0.6^{\mathrm{a}}$ & $36.2 \pm 3.0^{\mathrm{a}}$ \\
Sodium propionate (SP) & - & $14.7 \pm 1.0^{\mathrm{b}}$ \\
\hline
\end{tabular}

Means of two repeated experiments are shown. Mean disease severity (lesion diameter) on control (uncoated) fruit was $6.8 \pm 0.5 \mathrm{~mm}$ and $22.4 \pm 1.9 \mathrm{~mm}$ for experiments with HPMC-OA and HPMC-BW coatings, respectively. Means in columns with different letters are significantly different according to Fisher's protected LSD test $(p<0.05)$ applied after an ANOVA. 
In the case of disease severity, HPMC-OA coatings containing PC and SB significantly reduced the lesion diameter (by 28 and 22\%, respectively) in comparison to uncoated control fruit. Coatings formulated with ammonium carbonate (AC) and SEP reduced ABS severity by 12 and $2 \%$, respectively, while the rest of the coatings did not reduce it at all (Table 3). However, the HPMC-BW coatings without any preservative and with SEP significantly reduced ABS severity on inoculated persimmons by 26 and $36 \%$, respectively. Since ABS incidence and severity on both control (uncoated) and coated persimmons were very low after 7 days of incubation irrespective of the coating treatment (data not shown), it can be confirmed that the activity of the edible coatings was fungistatic rather than fungicidal, because ABS was delayed but not completely inhibited and both incidence and severity increased with incubation time.

\subsection{Effect of Coatings on Fruit Quality}

\subsubsection{Weight Loss}

Figure 2 shows the weight loss of coated and uncoated samples stored for 15 and 30 days at $1{ }^{\circ} \mathrm{C}$ plus 7 days of shelf life at $20^{\circ} \mathrm{C}$. As expected, weight loss increased with storage time to values that ranged between 2.3 and $3.9 \%$ at the end of the storage period. Only the coatings formulated with HPMC-BW (i.e., with and without antifungal food additives) significantly reduced the weight loss of 'Rojo Brillante' persimmons by around $20 \%$ compared to control samples, and the addition of the salts had no effect on weight loss. However, the HPMC-OA formulations increased the weight loss of coated persimmons compared to control samples, being greater in the formulation without antifungal food additives than in those containing the GRAS salts $(p<0.05)$.

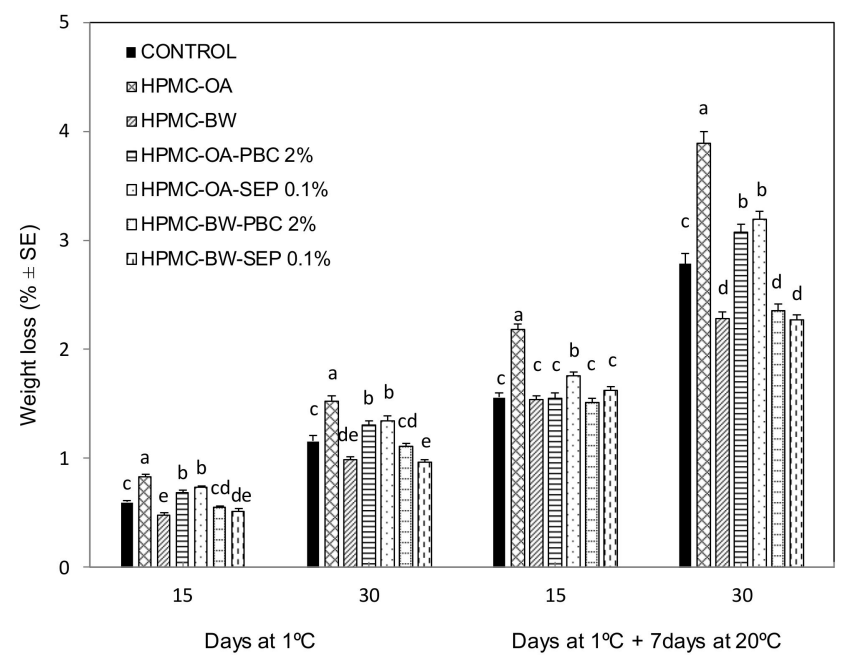

Figure 2. Weight loss of 'Rojo Brillante' persimmons uncoated (control) or coated with hydroxypropyl methylcellulose (HPMC)-oleic acid (OA) or HPMC-beeswax (BW) edible composite coatings containing potassium bicarbonate (PBC) or sodium ethyl paraben (SEP) and stored for up to 30 days at $1{ }^{\circ} \mathrm{C}$ followed by 7 days of shelf life at $20{ }^{\circ} \mathrm{C}$. For each storage period, columns with different letters are significantly different according to Fisher's protected LSD test $(p<0.05)$ applied after an ANOVA.

\subsubsection{Fruit Firmness}

Flesh firmness of coated and uncoated persimmons at the end of cold storage at $1^{\circ} \mathrm{C}$ plus 7 days of shelf life at $20^{\circ} \mathrm{C}$, is shown in Figure 3. Cold storage resulted in a significant loss of firmness with respect to values at harvest $(36.8 \pm 7.4 \mathrm{~N})$, with values in the range of 5-14 $\mathrm{N}$ after 30 days at $1{ }^{\circ} \mathrm{C}$ plus 7 days at $20^{\circ} \mathrm{C}$. 


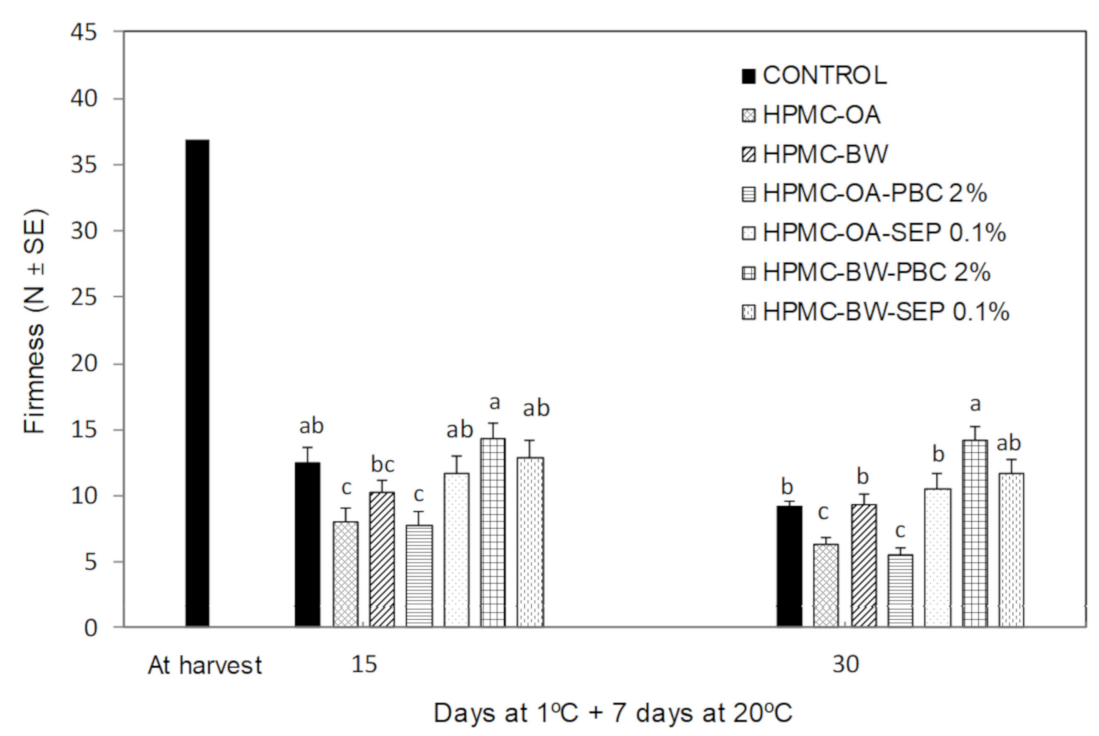

Figure 3. Firmness of 'Rojo Brillante' persimmons uncoated (control) or coated with hydroxypropyl methylcellulose (HPMC)-oleic acid (OA) or HPMC-beeswax (BW) edible composite coatings containing potassium bicarbonate (PBC) or sodium ethyl paraben (SEP) and stored for up to 30 days at $1{ }^{\circ} \mathrm{C}$, followed by 7 days of shelf life at $20^{\circ} \mathrm{C}$. For each storage period, columns with different letters are significantly different according to Fisher's protected LSD test $(p<0.05)$ applied after an ANOVA.

\subsubsection{Respiration Rate}

Figure 4 shows respiration ( $\mathrm{CO}_{2}$ production) of coated and uncoated 'Rojo Brillante' persimmons at harvest and after 15 and 30 days of storage at $1{ }^{\circ} \mathrm{C}$ plus 7 days of shelf life at $20^{\circ} \mathrm{C} . \mathrm{CO}_{2}$ production of uncoated persimmons was maintained during storage when compared with the initial value $(p>0.05)$. After 15 days of cold storage plus shelf life, measurements were characterized by a high variability (values ranged between 7 and $11 \mathrm{mg} \mathrm{CO} / \mathrm{kg} \mathrm{h}$ ), which might be attributed to the fruit-to-fruit variability, and there were no significant differences among treatments $(p>0.05)$. However, at the end of the storage and shelf-life period, $\mathrm{CO}_{2}$ production of coated samples was significantly lower than that of the uncoated samples, indicating that the coatings reduced persimmon respiration.

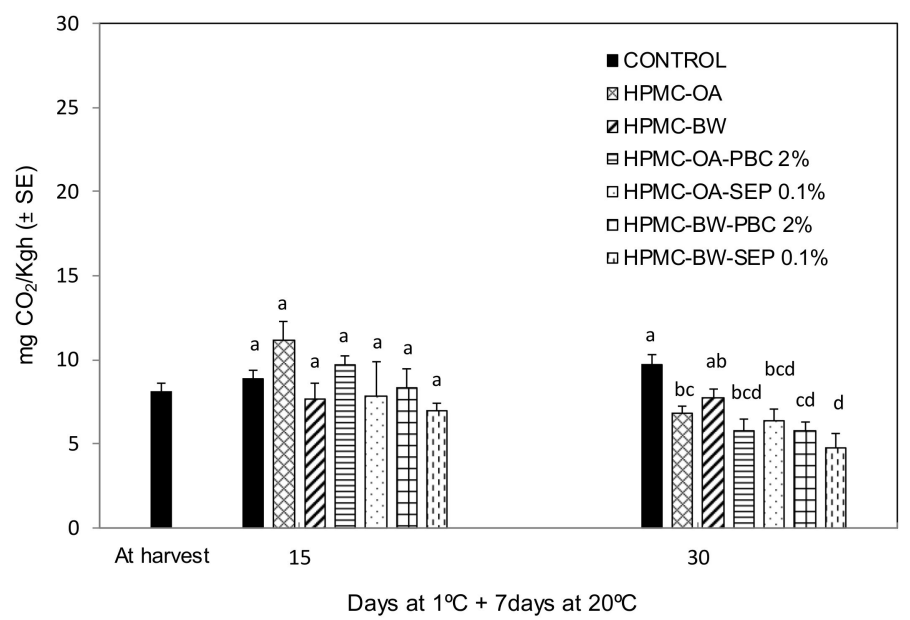

Figure 4. Respiration rate of 'Rojo Brillante' persimmons uncoated (control) or coated with hydroxypropyl methylcellulose (HPMC)-oleic acid (OA) or HPMC-beeswax (BW) edible composite coatings containing potassium bicarbonate (PBC) or sodium ethyl paraben (SEP) and stored for up to 30 days at $1{ }^{\circ} \mathrm{C}$, followed by 7 days of shelf life at $20^{\circ} \mathrm{C}$. For each storage period, columns with different letters are significantly different according to Fisher's protected LSD test $(p<0.05)$ applied after an ANOVA. 


\section{Discussion}

The antifungal performance of the coatings was evaluated according to the reduction in disease incidence and severity on coated persimmons previously inoculated with $\mathrm{A}$. alternata. This methodology allowed the assessment of the curative activity of the antifungal coatings. This was necessary because ABS is a postharvest disease caused mainly by latent field infections, so effective postharvest antifungal treatments need to control (cure) infections already established in the fruit.

As previously reported, the activity of the edible coatings was fungistatic rather than fungicidal [26]. This mode of action is typical of antifungal postharvest treatments based on low-toxicity chemicals or natural compounds and contrasts strongly with the fungicidal mode of action of the highly toxic conventional synthetic chemical fungicides $[26,27]$. The effectiveness of low-toxicity, fungistatic treatments is greatly affected by the complexity of the interactions between pathogen, fruit host and environment that define the disease triangle, and even more in the case of postharvest diseases that, like persimmon ABS, are mainly caused by field-latent infections. Conidia of A. alternata can directly infect intact young fruit developing in the tree during the entire fruit-growing season. In addition, near harvest, the fungus can also infect mature fruit through peel microcracks mostly produced in the calyx area, under the sepals [28]. In any case, fungal growth and consequent disease symptoms (superficial black spots) are only observed after harvest, especially after shelf life following long periods of cold storage [4]. Therefore, many different factors can affect the final incidence of ABS on persimmons and many of them will affect, in turn, the effectiveness of fungistatic postharvest treatments, among the most important being those related to the fruit host characteristics and its susceptibility to the disease. This may contribute to explaining why the effectiveness of particular postharvest alternative antifungal treatments can be different against diseases caused by the same fungal pathogen on different fruit hosts. In a previous study from our group to select appropriate antifungal HPMC-BW edible coatings formulated with food preservatives for the control of ABS on cherry tomatoes, the best results after incubation of coated fruit at $20^{\circ} \mathrm{C}$ were obtained with coatings containing $2.0 \% \mathrm{SB}, \mathrm{SEP}$ or SMP [8]. When these coatings were evaluated during cold storage, SEP and SB coatings were the most effective in reducing ABS severity, with reductions of around 65\% [9]. In the present work, HPMC-OA and HPMC-BW coatings containing SEP were also effective in reducing the incidence of ABS on 'Rojo Brillante' persimmon, with reductions of 36 and 53\%, respectively (Figure 1). However, SMP was not effective to control ABS on inoculated persimmons when incorporated into the HPMC-OA matrix, and efficacy of the HPMC-OA matrix with SB was also poor $(18 \%$ reduction compared to control samples, $p<0.05)$. Similarly, the present results also show differences in the antifungal performance of $\mathrm{PBC}$ depending on the coating matrix into which it was incorporated, being highly effective when it was incorporated into the HPMC-OA coating ( $60 \%$ incidence reduction), and not effective in combination with the HPMC-BW coating, although it was incorporated to the former at a lower concentration (i.e., 1 and $2 \%$ PBC in the HPMC-OA and HPMC-BW matrixes, respectively). Although not in the specific case of persimmons, $\mathrm{PBC}$ has been previously reported as effective to reduce postharvest disease caused by Alternaria spp. on some fresh horticultural products $[29,30]$. Although the mode of action of PBC, SEP or other GRAS salts for fungal disease control has not been completely elucidated, some researchers suggest that it is fungistatic rather than fungicidal, which explains why their effectiveness is considerably lower than that of conventional chemical fungicides. Treatment with PBC exerted direct activity against A. alternata by affecting both spore germination and mycelial growth, and particularly germ tube elongation. Furthermore, $\mathrm{PBC}$ application resulted in shrinkage and collapse of the hyphae and spores of the fungus, and consequent inability to sporulate [29]. SEP might also interfere in both the germinative and vegetative phases of fungal development, but spore germination is much more susceptible to SEP than fungal vegetative growth. It is generally believed that SEP has an inhibitory effect on membrane transport and mitochondrial function processes, and the $\mathrm{pH}$ in the site of infection plays a crucial role in 
antifungal activity [31]. The present results confirm the large number of factors that must be considered when formulating new edible coatings with alternative antifungal ingredients. While the cited complex interactions between host, pathogen, and environment that occur during disease development determine the in vivo inhibition ability of a treatment, specific interactions between the antifungal agent and the other coating ingredients may modify its inherent antifungal activity and/or its availability in the fruit surface. Thus, for example, factors involved in the release of the agent to the fruit peel may have a great influence on the antifungal performance of the coating. In general, the release of antimicrobial agents from polymeric matrixes involves the diffusion of the active ingredient within the polymer matrix, the solubility of the agent in the food surface, and the diffusivity into the bulk food [32]. In these steps, factors such as polymer-antifungal interaction, fruit skin resistance to diffusion of the antifungal agent, $\mathrm{pH}$, humidity and temperature of the system, among others, exert an important effect in the release and diffusivity ability of the antifungal compound [8]. Thus, for example, different diffusion coefficients have been reported for potassium sorbate incorporated into various biopolymers. In these studies, the diffusion model followed Fick's law in k-carrageenan, gelatin, and cornstarchbased antimicrobial films $[33,34]$ and a non-Fickian diffusion mechanism in whey protein films [35]. Furthermore, diffusion of potassium sorbate was found to be non-affected by the $\mathrm{pH}$ of the medium in k-carrageenan [33] and corn starch films [36], whereas it increased in gelatin films [34] and decreased in whey protein films [37] as the pH of the medium decreased.

Considering the overall effect of the tested edible coatings on ABS reduction on artificially inoculated 'Rojo Brillante' persimmons, 2\% PBC and 0.1\% SEP were selected as the two antifungal agents to be incorporated into HPMC-OA and HPMC-BW coatings to evaluate their performance under commercial prolonged cold-storage conditions and their effects on the fruit physicochemical quality. Coating matrixes without antifungal ingredients were also evaluated (Table 2). The edible coating formulations without food preservatives had a slightly acid $\mathrm{pH}(5.46-5.58)$ that increased to neutral (6.72-7.60) or basic $\mathrm{pH}$ values (8.28-8.84) when $0.1 \%$ SEP and $2 \%$ PBC, respectively, were incorporated into the HPMC-based coatings. On the other hand, viscosities were in the range of 80-100 and 140-200 mPa.s for HPMC-OA and HPMC-BW coating formulations, respectively. Differences in viscosity can be attributed to the concentration of HPMC in the emulsions (i.e., higher HPMC content in HPMC-BW than in HPMC-OA formulations) and the interactions among the different ingredients. In both cases, emulsions were stable and ensured complete coverage of the surface of the persimmon fruit. Overall, the values of $\mathrm{pH}$ and viscosity for HPMC-BW-based formulations are comparable to those reported in previous works for similar HPMC-based emulsions developed for cherry tomatoes [8,9] and plums [6].

In general, coatings containing hydrophobic compounds, deposited as an additional layer over the peel, are expected to improve the moisture resistance of the fruit [20]. However, several works have confirmed that the effect of edible coatings on fruit weight loss depends on the intrinsic characteristics of both the coating and the fruit. Thus, for example, the addition of lipids to biopolymers did not reduce the weight loss of coated commodities, such as cherries and cucumbers [38], apples [39], plums [40], and oranges [41], among others. In the case of persimmon fruit, recent research shows different fruit behavior depending on coating formulation and cultivar. Thus, Kingwascharapong et al. [42] reported that gelatin coatings formulated with frog skin oil reduced the weight loss of 'Fuyu' persimmons only during 3 days of storage at $25^{\circ} \mathrm{C}$, whereas no significant differences were observed between control and coated samples after 9 days of storage. However, 'Fuyu' persimmons coated with $10 \%$ gum Arabic without incorporating any hydrophobic ingredient to the formulation effectively reduced weight loss during 20 days of storage at $20{ }^{\circ} \mathrm{C}$ [43]. In the case of 'Rojo Brillante' persimmons, the effect of starch-gellan based coatings formulated with thyme essential oil as an antifungal agent, incorporated either by direct emulsification or encapsulated in lecithin liposomes, on weight loss reduction 
depended on the concentration of the essential oil and the presence of lecithin [23]. Thus, only the starch-gellan coating formulated at the lowest essential oil content and without lecithin significantly reduced the weight loss of coated persimmons stored for 14 days at $25^{\circ} \mathrm{C}$. In the same work, the presence of Tween 85 in the starch-gellan formulations increased the weight loss of coated 'Golden Delicious' apples compared to uncoated fruit, which was attributed to the interactions of Tween 85 with the cuticular waxes, as well as its effect on the decrease in the cohesion forces of the starch-gellan matrix, limiting chain packing. In our case, the HPMC-OA coatings were formulated with Tween 80 as an emulsifier and, therefore, this could also account for the higher weight loss of persimmons coated with these formulations (Figure 2). As is known, cuticular waxes are embedded in the cutin forming a continuous layer and, therefore, they play an important role in fruit cuticle permeability and wettability [44]. Given the amphiphilic nature of surfactants, they could also modify the overall barrier properties of the wax-coating assembly by partially removing the natural wax of the fruit cuticle and increasing moisture loss.

On the other hand, several works confirmed that, in general, the addition of food additives or GRAS salts to HPMC-based coatings greatly affects the moisture barrier properties of stand-alone films or coatings when applied to different fruit such as citrus, table grapes and cherry tomatoes, increasing water vapor permeability and weight loss $[10,15,20,45]$. In the present work, the incorporation of $2 \%$ PBC or $0.1 \%$ SEP to the HPMC-BW matrix did not affect the moisture barrier of the coating formulation. However, in the case of the HPMC-OA coating matrix, the addition of these GRAS salts improved the moisture barrier of the coating compared to the unmodified formulation, although in any case these coatings reduced the weight loss of coated persimmons compared to control samples. This fact illustrates the importance of considering specific interactions of particular salts with coating ingredients such as surfactants, as they might affect the interfacial behavior and wettability of the emulsion systems [46]. Furthermore, considering that the morphology of the fruit peel and the composition of cuticular waxes vary considerably between plant species and cultivars, this can also explain the important differences in weight loss found in the literature when different fruit was treated with similar antifungal coatings. For instance, similar HPMC-lipid coatings containing organic acid salts and their mixtures significantly reduced weight loss in coated 'Ortanique' mandarins during long-term cold storage [17], but did not reduce that of 'Valencia' oranges, and some coatings even induced a significant increase in weight loss of this cultivar [16].

Fruit firmness is the most important attribute to rate the quality of 'Rojo Brillante' persimmons when marketed after astringency removal. Like other persimmon cultivars, 'Rojo Brillante' fruit are chilling-sensitive when stored at temperatures below $11^{\circ} \mathrm{C}$ [3]. Fruit softening and gelling are the main symptoms of chilling injury in persimmons, and they manifest when fruit is transferred from refrigeration to shelf-life temperatures [3]. The present results confirmed the sensitivity to chilling injury of this cultivar, with a loss of firmness of around $75 \%$ on control samples at the end of the storage and shelf-life period (Figure 3). The effect of the HPMC-lipid-based edible coatings on fruit firmness depended on coating composition. In general, HPMC-BW coatings performed better than HPMC-OA coatings, in agreement with their behavior regarding weight loss. Overall, the most effective coating for maintaining fruit firmness was HPMC-BW-PBC, with firmness of around $14 \mathrm{~N}$ after 30 days of cold storage plus 7 days at $20^{\circ} \mathrm{C}$. Although at present a minimum degree of firmness to commercialize the cultivar 'Rojo Brillante' as firm has not been recommended by the industry, values below $10 \mathrm{~N}$ following storage and marketing are considered unsuitable from a commercial point of view [3,47]. Therefore, the HPMC-BW coating containing $2 \%$ PBC could be used on a commercial scale.

In general, the effect of edible coatings maintaining fruit firmness has been related to the barrier to gases, which translates into a reduction in fruit respiration rate and, therefore, in all the metabolic processes associated with respiration [19]. In the case of persimmon fruit, Saleem et al. [43] reported a reduction in the activity of cell wall- degrading enzymes (i.e., polygalacturonase, pectin methylesterase and cellulase) and membrane leakage in 
'Fuyu' persimmons coated with gum Arabic compared to control samples during 20 days of storage at $20^{\circ} \mathrm{C}$. However, these workers did not evaluate either the firmness or the respiration rate of coated persimmons. In another research work, no significant differences were found in the firmness of 'Fuyu' persimmons coated with gelatin-based frog skin oil compared to uncoated samples stored for up to 9 days at $25^{\circ} \mathrm{C}$, in spite of a reduction in respiration rate of the coated samples [42]. In the case of 'Rojo Brillante' persimmons, starch-gellan coatings formulated with and without thyme essential oil maintained higher fruit firmness than uncoated fruit for 14 days of storage at $25^{\circ} \mathrm{C}$, but did not modify the respiration rate [23]. In this context, some reports suggested that cuticle composition and architecture may also play a key role in the changes of fruit firmness [44]. For example, a study of fruit cuticular membranes isolated from 27 persimmon cultivars revealed that density and chemical composition could greatly explain the mechanical properties of the different cultivars [48]. In our case, the better performance of HPMC-BW coatings compared to HPMC-OA coatings maintaining fruit firmness could also be related to a partial removal of the cuticle or a partial modification of cuticle composition due to the action of the HPMC-OA coatings.

One of the main functions of coatings on fresh fruit is related to their ability to create a barrier against oxygen diffusion between the fruit and the environment, which translates into lower respiration rates and metabolic activity. Therefore, the effect of edible coatings delaying changes related to fruit ripening and senescence during storage, such as softening, color change, and reduction in acidity, as well as a reduction of some physiological disorders, is generally attributed to their effect on fruit respiration reduction. In this sense, a number of edible coatings have been developed that effectively delayed respiration rate and extended the postharvest life of fresh produce [12,49]. However, their effect greatly depends on the commodity, coating composition, thickness and environmental conditions [41,50-52]. In the case of persimmon fruit, gelatin-based frog skin oil edible coatings delayed the climacteric peak of 'Fuyu' persimmons and significantly reduced the respiration rate during 6 days of storage at $25^{\circ} \mathrm{C}$, although no effect was observed on fruit firmness [42]. In contrast, starch-gellan edible coatings did not modify the respiration rate of 'Rojo Brillante' persimmons after 14 days of storage at $20^{\circ} \mathrm{C}$, but maintained higher fruit firmness than uncoated samples [23]. In the present work, both HPMC-OA and HPMC-BW-based coatings reduced the respiration rate of 'Rojo Brillante' persimmons after prolonged storage at $1^{\circ} \mathrm{C}$ plus shelf life (Figure 4). However, only the HPMC-BW-based coatings effectively reduced firmness loss during storage, which confirmed that cuticle composition and architecture may also play a key role in the changes in fruit firmness.

\section{Conclusions}

The results of this work confirm the importance of coating composition to controlling postharvest decay and maintaining fruit quality for each specific commodity, target pathogen and storage conditions. While HPMC-OA coatings amended with PBC, PC or SEP were effective to reduce ABS incidence and severity during incubation at $20^{\circ} \mathrm{C}$ in artificially inoculated 'Rojo Brillante' persimmons, only the HPMC-BW coating containing SEP effectively reduced the disease. When evaluating fruit quality, HPMC-BW coatings with and without PBC or SEP were more effective in reducing fruit weight and firmness losses after cold storage at $1{ }^{\circ} \mathrm{C}$ and shelf life at $20^{\circ} \mathrm{C}$ than HPMC-OA coatings. To our knowledge, this is the first report on the potential of antifungal edible coatings to extend the postharvest life of persimmon fruit stored at low temperatures. Overall, the HPMC-BW edible coating containing SEP as an antifungal agent could be a promising industrial treatment to control ABS and maintain the postharvest quality of 'Rojo Brillante' persimmon destined for both domestic and export markets. Further research should focus on improving the physical characteristics of this HPMC-BW-SEP edible composite coating, in order to enhance its performance during cold storage, evaluate its effectiveness for ABS reduction in semi-commercial or commercial trials with naturally infected fruit, and 
determine the effect of coating application on the outcome of the commercial postharvest deastringency treatment conducted by exposure of fruit to high concentrations of $\mathrm{CO}_{2}$.

Author Contributions: Conceptualization: M.B.P.-G. and L.P.; methodology: M.B.P.-G. and L.P.; validation: A.F.-C., L.P. and M.B.P.-G.; formal analysis: A.F.-C., V.T., A.G. and M.A.-S.; investigation: A.F.-C., V.T., A.G., M.A.-S., M.B.P.-G. and L.P.; resources: L.P. and M.B.P.-G.; data curation: A.F.-C., M.B.P.-G. and L.P.; writing—original draft preparation: A.F.-C.; writing—review and editing: A.F.-C., L.P. and M.B.P.-G.; visualization: A.F.-C.; supervision: L.P. and M.B.P.-G.; project administration: M.B.P.-G. and L.P.; funding acquisition: M.B.P.-G. and L.P. All authors have read and agreed to the published version of the manuscript.

Funding: This work was funded by the Spanish "National Institute for Agricultural and Food Research and Technology" (INIA, Project RTA2015-00037-C02-00), the IVIA (Project No. 51910) and the European Union through the European Regional Development Fund (ERDF) of the Generalitat Valenciana 2014-2020. Asunción Fernández-Catalán research scholarship is supported by the IVIA and the European Social Fund (ESF) (IVIA-ESF 2018 Grant No. 25).

Institutional Review Board Statement: Not applicable.

Informed Consent Statement: Not applicable.

Data Availability Statement: The data presented in this study belong to the IVIA and are available on request from the corresponding author.

Conflicts of Interest: The authors declare no conflict of interest.

\section{References}

1. FAOSTAT Food and Agriculture Organization of the United Nations. Statistics. Available online: http://www.fao.org/faostat/ en/\#data/QC (accessed on 11 January 2021).

2. ISAV Informe Sector Agrario Valenciano. Producción, Industrias y Consumo Agroalimentarios. Available online: http:/ /www. agroambient.gva.es/es/informes-del-sector-agrario-valenciano (accessed on 11 January 2021).

3. Arnal, L.; Del Río, M.A. Effect of cold storage and removal astringency on quality of persimmon fruit (Diospyros kaki, L.) cv. Rojo brillante. Food Sci. Technol. Int. 2004, 10, 179-185. [CrossRef]

4. Prusky, D. Etiology and histology of Alternaria rot of persimmon fruits. Phytopatholy 1981, 71, 1124. [CrossRef]

5. Palou, L.; Montesinos-Herrero, C.; Tarazona, I.; Besada, C.; Taberner, V. Incidence and etiology of postharvest fungal diseases of persimmon (Diospyros kaki thunb. cv. Rojo Brillante) in Spain. Plant Dis. 2015, 99, 1416-1425. [CrossRef] [PubMed]

6. Karaca, H.; Pérez-Gago, M.B.; Taberner, V.; Palou, L. Evaluating food additives as antifungal agents against Monilinia fructicola in vitro and in hydroxypropyl methylcellulose-lipid composite edible coatings for plums. Int. J. Food Microbiol. 2014, 179, 72-79. [CrossRef]

7. Youssef, K.; Ligorio, A.; Sanzani, S.M.; Nigro, F.; Ippolito, A. Control of storage diseases of citrus by pre- and postharvest application of salts. Postharvest Biol. Technol. 2012, 72, 57-63. [CrossRef]

8. Fagundes, C.; Pérez-Gago, M.B.; Monteiro, A.R.; Palou, L. Antifungal activity of food additives in vitro and as ingredients of hydroxypropyl methylcellulose-lipid edible coatings against Botrytis cinerea and Alternaria alternata on cherry tomato fruit. Int. J. Food Microbiol. 2013, 166, 391-398. [CrossRef] [PubMed]

9. Fagundes, C.; Palou, L.; Monteiro, A.R.; Pérez-Gago, M.B. Hydroxypropyl methylcellulose-beeswax edible coatings formulated with antifungal food additives to reduce alternaria black spot and maintain postharvest quality of cold-stored cherry tomatoes. Sci. Hortic. 2015, 193, 249-257. [CrossRef]

10. Valencia-Chamorro, S.A.; Pérez-Gago, M.B.; del Río, M.A.; Palou, L. Curative and preventive activity of hydroxypropyl methylcellulose-lipid edible composite coatings containing antifungal food additives to control citrus postharvest green and blue molds. J. Agric. Food Chem. 2009, 57, 2770-2777. [CrossRef]

11. De Souza, E.L.; Lundgren, G.A.; de Oliveira, K.A.R.; Berger, L.R.R.; Magnani, M. An analysis of the published literature on the effects of edible coatings formed by polysaccharides and essential oils on postharvest microbial control and overall quality of fruit. Compr. Rev.Food Sci. Food Saf. 2019, 18, 1947-1967. [CrossRef]

12. Maringgal, B.; Hashim, N.; Tawakkal, I.S.M.A.; Mohamed, M.T.M. Recent advance in edible coating and its effect on fresh/freshcut fruits quality. Trends Food Sci. Technol. 2020, 96, 253-267. [CrossRef]

13. Ribeiro, A.M.; Estevinho, B.N.; Rocha, F. Preparation and incorporation of functional ingredients in edible films and coatings. Food Bioprocess Technol. 2021, 14, 209-231. [CrossRef]

14. Valencia-Chamorro, S.A.; Palou, L.; del Río, M.A.; Pérez-Gago, M.B. Antimicrobial edible films and coatings for fresh and minimally processed fruits and vegetables: A review. Crit. Rev. Food Sci. Nutr. 2011, 51, 872-900. [CrossRef] [PubMed] 
15. Valencia-Chamorro, S.A.; Palou, L.; Del Río, M.A.; Pérez-Gago, M.B. Inhibition of Penicillium digitatum and Penicillium italicum by hydroxypropyl methylcellulose-lipid edible composite films containing food additives with antifungal properties. J. Agric. Food Chem. 2008, 56, 11270-11278. [CrossRef] [PubMed]

16. Valencia-Chamorro, S.A.; Pérez-Gago, M.B.; del Río, M.A.; Palou, L. Effect of antifungal hydroxypropyl methylcellulose (HPMC)lipid edible composite coatings on postharvest decay development and quality attributes of cold-stored 'Valencia' oranges. Postharvest Biol. Technol. 2009, 54, 72-79. [CrossRef]

17. Valencia-Chamorro, S.A.; Pérez-Gago, M.B.; Del Río, M.A.; Palou, L. Effect of antifungal hydroxypropyl methylcellulose-lipid edible composite coatings on Penicillium decay development and postharvest quality of cold-stored 'Ortanique' mandarins. $J$. Food Sci. 2010, 75, 418-426. [CrossRef] [PubMed]

18. Guimarães, J.E.R.; de la Fuente, B.; Pérez-Gago, M.B.; Andradas, C.; Carbó, R.; Mattiuz, B.H.; Palou, L. Antifungal activity of GRAS salts against Lasiodiplodia theobromae in vitro and as ingredients of hydroxypropyl methylcellulose-lipid composite edible coatings to control Diplodia stem-end rot and maintain postharvest quality of citrus fruit. Int. J. Food Microbiol. 2019, 301, 9-18. [CrossRef]

19. Gunaydin, S.; Karaca, H.; Palou, L.; de la Fuente, B.; Pérez-Gago, M.B. Effect of hydroxypropyl methylcellulose-beeswax composite edible coatings formulated with or without antifungal agents on physicochemical properties of plums during cold storage. J. Food Qual. 2017, 2017. [CrossRef]

20. Fagundes, C.; Palou, L.; Monteiro, A.R.; Pérez-Gago, M.B. Effect of antifungal hydroxypropyl methylcellulose-beeswax edible coatings on gray mold development and quality attributes of cold-stored cherry tomato fruit. Postharvest Biol. Technol. 2014, 92, 1-8. [CrossRef]

21. Aguirre-Joya, J.A.; Cerqueira, M.A.; Ventura-Sobrevilla, J.; Aguilar-Gonzalez, M.A.; Carbó-Argibay, E.; Castro, L.P.; Aguilar, C.N. Candelilla wax-based coatings and films: Functional and physicochemical characterization. Food Bioprocess Technol. 2019, 12, 1787-1797. [CrossRef]

22. Gong, L.; Zhao, Z.; Yin, C.; Gupta, V.K.; Zhang, X.; Jiang, Y. Synergistic interaction of natamycin with carboxymethyl chitosan for controlling Alternata alternara, a cause of black spot rot in postharvest jujube fruit. Postharvest Biol. Technol. 2019, 156, 110919. [CrossRef]

23. Sapper, M.; Palou, L.; Pérez-Gago, M.B.; Chiralt, A. Antifungal starch-gellan edible coatings with thyme essential oil for the postharvest preservation of apple and persimmon. Coatings 2019, 9, 333. [CrossRef]

24. Rodriguez-Garcia, I.; Cruz-Valenzuela, M.R.; Silva-Espinoza, B.A.; Gonzalez-Aguilar, G.A.; Moctezuma, E.; Gutierrez-Pacheco, M.M.; Tapia-Rodriguez, M.R.; Ortega-Ramirez, L.A.; Ayala-Zavala, J.F. Oregano (Lippia graveolens) essential oil added within pectin edible coatings prevents fungal decay and increases the antioxidant capacity of treated tomatoes. J. Sci. Food Agric. 2016, 96, 3772-3778. [CrossRef]

25. Martínez-Blay, V.; Pérez-Gago, M.B.; de la Fuente, B.; Carbó, R.; Palou, L. Edible coatings formulated with antifungal GRAS salts to control citrus anthracnose caused by Colletotrichum gloeosporioides and preserve postharvest fruit quality. Coatings 2020, 10, 730 [CrossRef]

26. Palou, L.; Ali, A.; Fallik, E.; Romanazzi, G. GRAS, plant- and animal-derived compounds as alternatives to conventional fungicides for the control of postharvest diseases of fresh horticultural produce. Postharvest Biol. Technol. 2016, 122, 41-52. [CrossRef]

27. De Souza, E.; Ramos, L.; Marín, A.; Pérez-Gago, M.B.; Palou, L. Chitosan and other edible coatings for postharvest disease control. In Postharvest Pathology of Fresh Horticultural Produce; Palou, L., Smilanick, J.L., Eds.; CRC Press: Boca Raton, FL, USA, 2020; pp. 677-712, ISBN 9781315209180.

28. Palou, L.; Teksur, P.K.; Cao, S.; Karaoglanidis, G.; Vicent, A. Pomegranate, persimmon and loquat. In Postharvest Pathology of Fresh Horticultural Produce; Palou, L., Smilanick, J.L., Eds.; CRC Press: Boca Raton, FL, USA, 2020; pp. 187-226, ISBN 9781315209180.

29. Fallik, E.; Grinberg, S.; Ziv, O. Potassium bicarbonate reduces postharvest decay development on bell pepper fruits. J. Hort. Sci. 1997, 72, 35-41. [CrossRef]

30. Sanzani, S.M.; Djenane, F.; Incerti, O.; Admane, N.; Mincuzzi, A.; Ippolito, A. Mycotoxigenic fungi contaminating greenhousegrown tomato fruit and their alternative control. Eur. J. Plant Pathol. 2021. [CrossRef]

31. Moscoso-Ramírez, P.A.; Montesinos-Herrero, C.; Palou, L. Control of citrus postharvest penicillium molds with sodium ethylparaben. Crop Prot. 2013, 46, 44-51. [CrossRef]

32. Han, J.H.; Floros, J.D. Potassium sorbate diffusivity in American processed and Mozzarella cheeses. J. Food Sci. 1998, 63, 435-437. [CrossRef]

33. Choi, J.H.; Choi, W.Y.; Cha, D.S.; Chinnan, M.J.; Park, H.J.; Lee, D.S.; Park, J.M. Diffusivity of potassium sorbate in k-carrageenan based antimicrobial film. LWT Food Sci. Technol. 2005, 38, 417-423. [CrossRef]

34. Wang, H.; He, J.; Sun, H. Diffusion analysis and modeling of potassium sorbate in gelatin based antimicrobial film. J. Mater. Sci. Chem. Eng. 2016, 4, 1-7. [CrossRef]

35. Ozdemir, M.; Floros, J.D. Analysis and modeling of potassium sorbate diffusion through edible whey protein films. J. Food Eng. 2001, 47, 149-155. [CrossRef]

36. López, O.V.; Giannuzzi, L.; Zaritzky, N.E.; García, M.A. Potassium sorbate controlled release from corn starch films. Mater. Sci. Eng. C Mater. Biol. Appl. 2013, 33, 1583-1591. [CrossRef] [PubMed] 
37. Moditsi, M.; Lazaridou, A.; Moschakis, T.; Biliaderis, C.G. Modifying the physical properties of dairy protein films for controlled release of antifungal agents. Food Hydrocoll. 2014, 39, 195-203. [CrossRef]

38. Baldwin, E.A.; Hagenmaier, R.D.; Baker, R.A. Use of lipids in coatings for food products. Food Technol. 1997, 51, 56-64.

39. Bai, J.; Baldwin, E.A.; Hagenmaier, R.H. Alternatives to shellac coatings provide comparable gloss, internal gas modification, and quality for 'Delicious' apple fruit. HortScience 2002, 37, 559-563. [CrossRef]

40. Navarro-Tarazaga, M.L.; Sothornvit, R.; Pérez-Gago, M.B. Effect of plasticizer type and amount on hydroxypropyl methylcellulosebeeswax edible film properties and postharvest quality of coated plums (Cv. Angeleno). J. Agric. Food Chem. 2008, 56, 9502-9509. [CrossRef]

41. Contreras-Oliva, A.; Rojas-Argudo, C.; Pérez-Gago, M.B. Effect of solid content and composition of hydroxypropyl methylcellulose-lipid edible coatings on physico-chemical and nutritional quality of 'Oronules' mandarins. J. Sci. Food Agric. 2012, 92, 794-802. [CrossRef]

42. Kingwascharapong, P.; Arisa, K.; Karnjanapratum, S.; Tanaka, F.; Tanaka, F. Effect of gelatin-based coating containing frog skin oil on the quality of persimmon and its characteristics. Sci. Hortic. 2020, 260, 108864. [CrossRef]

43. Saleem, M.S.; Ejaz, S.; Anjum, M.A.; Nawaz, A.; Naz, S.; Hussain, S.; Ali, S.; Canan, I. Postharvest application of gum Arabic edible coating delays ripening and maintains quality of persimmon fruits during storage. J. Food Process. Preserv. 2020, 44, 1-13. [CrossRef]

44. Lara, I.; Belge, B.; Goulao, L.F. The fruit cuticle as a modulator of postharvest quality. Postharvest Biol. Technol. 2014, 87, 103-112. [CrossRef]

45. Pastor, C.; Sánchez-González, L.; Marcilla, A.; Chiralt, A.; Cháfer, M.; González-Martínez, C. Quality and safety of table grapes coated with hydroxypropylmethylcellulose edible coatings containing propolis extract. Postharvest Biol. Technol. 2011, 60, 64-70. [CrossRef]

46. Kumar, S.; Mandal, A. Studies on interfacial behavior and wettability change phenomena by ionic and nonionic surfactants in presence of alkalis and salt for enhanced oil recovery. Appl. Surf. Sci. 2016, 372, 42-51. [CrossRef]

47. Salvador, A.; Cuquerella, J.; Martínez-Jávega, J.M.; Monterde, A.; Navarro, P. 1-MCP preserves the firmness of stored persimmon 'Rojo Brillante'. J. Food Sci. 2004, 69, snq69-snq73. [CrossRef]

48. Tsubaki, S.; Ozaki, Y.; Yonemori, K.; Azuma, J.I. Mechanical properties of fruit-cuticular membranes isolated from 27 cultivars of Diospyros kaki Thunb. Food Chem. 2012, 132, 2135-2139. [CrossRef]

49. Sharma, P.; Kehinde, B.A.; Kaur, S.; Vyas, P. Application of edible coatings on fresh and minimally processed fruits: A review. Nutr. Food Sci. 2019, 49, 713-738. [CrossRef]

50. Bai, J.; Hagenmaier, R.D.; Baldwin, E.A. Coating selection for 'Delicious' and other apples. Postharvest Biol. Technol. 2003, 28, 381-390. [CrossRef]

51. Cisneros-Zevallos, L.; Krochta, J.M. Dependence of coating thickness on viscosity of coating solution applied to fruits and vegetables by dipping method. J. Food Sci. 2003, 68, 503-510. [CrossRef]

52. Bai, J.; Plotto, A. Coatings for fresh fruits and vegetables. In Edible Coatings and Films to Improve Food Quality; Baldwin, E.A., Hagenmaier, R., Bai, J., Eds.; CRC Press: Boca Raton, FL, USA, 2011; pp. 185-242. ISBN 9781138198937. 